\title{
Reply letter
}

\author{
Marcela Barretto ${ }^{1}$
}

\author{
Lucia Martins Diniz ${ }^{1}$
}

DOI: http:/ /dx.doi.org/10.1590/abd1806-4841.2016910302

Dear Dr. Maria Eugenia Noviski Gallo,

Thank you for your suggestions.

In reply to your letter, we know the "Cadernos de Atenção Básica" - Vigilância em Saúde, $2^{a}$ edição revisada, of 2010. It is a more recent revision (2010), but it was not used in the reference because leprosy was described together with other infectious diseases: dengue, tracoma, tuberculosis and schistosomiasis; we believe a specific reference to Hansen's disease could be more adequate, therefore the Guia para o Controle da Hanseníase (Guide for Control of Leprosy), 2002.

As regards the BCG vaccine in contacts, it is true that the details about the use of vaccine doses is lacking, but the main intention was to promote a discussion encompassing its protective effect.
With respect to Tables 1 and 2 focusing the treatment of leprosy with polychemotherapy in children we decided to use them, subdividing the patients into zero - five-year-olds and six - 14-year-olds age groups, with the doses appropriate for those ages, as described in the Guia para o Controle da Hanseníase. In the Cadernos de Atenção Básica the therapeutic schemes for children do not explain the difference in doses of medications separating them according to age group, as demonstrated in the Guia para o Controle da Hanseníase, therefore we decided to use them.

Sincerely,

Lucia Martins Diniz and Marcela Barretto marcela_barretto@yahoo.com.br 